\title{
LA FILOSOFÍA COMO RAMA DE LA LITERATURA: ENTRE BORGES Y DELEUZE
}

Axel Cherniavsky *

Resumen: La relación de Borges con la filosofía parece haber sido objeto de tres interrogaciones: ¿Es acaso Borges un filósofo? ¿Cuál es su filosofía? ¿Qué hace con la filosofía? Sin embargo, no es seguro que en las respuestas a estas preguntas se explicite cuál es el valor de Borges para la filosofía. Se trata aquí de una pregunta diferente que, si la condición de filósofo de Borges es precisamente lo que se halla en juego, no podemos esperar contestarla desde su propia obra. Proponemos hacerlo a partir de la historia de la filosofía y la teoría del discurso filosófico de Gilles Deleuze. En efecto, creemos que es posible encontrar allí un modo novedoso de interpretar la famosa sentencia borgeana según la cual la filosofía sería una rama de la literatura.

Palabras clave: filosofía, literatura, estilo, concepto

Abstract: Borges's relationship with philosophy seems to have arisen three questions: Is Borges a philosopher? Which is his philosophy? What does he do with philosophy? However, it isn't certain that the answers to these questions specify the value of Borges for philosophy. This is a different question, which can't be answered from Borges's own work, precisely because it is its philosophical condition what is at stake. Therefore we propose to do it from the history of philosophy and philosophical discourse theory of Gilles Deleuze. Indeed, we believe that it is possible to find here a new way of interpreting Borges's famous sentence according to which philosophy would be a branch of literature.

Key words: Philosophy, literature, style, concept

* Doctor en Filosofía por la Universidad de París 1 Panthéon-Sorbonne y la Universidad de Buenos Aires. Actualmente realiza una investigación postdoctoral sobre el vínculo de la filosofía con su historia en las obras de Hegel y Deleuze como becario del CONICET, y se desempeña como docente en las cátedras de Filosofía contemporánea y Metafísica de la Facultad de Filosofía y Letras de la Universidad de Buenos Aires. 
Quizá a causa del carácter polémico de ciertas declaraciones (como la que reduce un sistema filosófico a una cierta coordinación de palabras) ${ }^{1}$, sin duda porque diversos temas típicamente filosóficos pueblan sus ficciones (como el tiempo, la memoria, la identidad, el conocimiento) ${ }^{2}$, se ha constituido ya, en el marco de la crítica borgeana, una tradición compuesta tanto por historiadores de la filosofía como por críticos literarios que interroga la relación de Jorge Luis Borges con la filosofía. Así, se lo ha considerado platónico y aristotélico, escéptico cuando la cuestión es indecidible, exponente de la fenomenología y hasta precursor de la deconstrucción. Se ha interrogado, previamente, si merece el título de filósofo -lo que dista de ser una evidencia para un autor de cuentos y poemas. Y cuando se le ha negado este título, se han examinado luego los motivos de la negativa: ¿qué es lo que hace Borges con la filosofía visto que, si no es un filósofo, la dos veces milenaria disciplina inunda buena parte de su literatura?

No es seguro, sin embargo, que las respuestas a todas estas preguntas arrojen algo de luz sobre el problema del valor de Borges para la filosofía. A lo sumo, se indica cuál es el valor de ésta para aquél. Ahora bien, si, filósofo o no, Borges ha hallado en la filosofía una fuente de inspiración, ¿no es de esperar que la filosofía reciba algo de él a cambio? ¿Qué podría ser? Tras examinar, desde este punto de vista, la pertinencia de preguntas como si Borges es o no un filósofo, cuál es su filosofía o qué uso hace de su historia, sugeriremos un modo de comprender en qué medida sus trabajos pueden enriquecer la disciplina. Para ello recurriremos a la historia de la filosofía y a la teoría del discurso filosófico de Gilles Deleuze, quien, en más de un punto, aunque salvando las distancias, parece haber oído y utilizado las enseñanzas borgeanas, tanto para leer como para escribir filosofía. Se tratará, en particular, de interpretar la idea según la cual la filosofía podría

1 Jorge Luis Borges, Discusión, "Avatares de la tortuga", en Obras completas, Barcelona, Emecé, 1996, t. I, p. 258. Salvo indicación contraria, los textos de Borges serán citados a partir de la presente edición de las obras completas, abreviada OC.

${ }^{2}$ Mencionemos respectivamente algunos textos célebres sólo a título de ejemplo: Historia de la eternidad (en OC, t. I, p. 318), "Funes el memorioso" (Ficciones, en OC, t. I, p. 485), "Borges y yo" (El hacedor, en $O C$, t. II, p. 186), "Tlön, Uqbar, OrbisTertius" (Ficciones, en OC, t. I, p. 429). 
ser una rama de la literatura ${ }^{3}$ ya no como, según el propio Borges afirmaba, indicio de un escepticismo esencial, ${ }^{4}$ sino desde la perspectiva de una metodología que excede la mera expresión y que concierne a la propia creación conceptual.

En efecto, una de las preguntas que al mismo tiempo aúna y divide a la crítica es cuál es la filosofía subyacente en la literatura borgeana. Un primer paso decisivo en esta dirección fue dado por el ya clásico libro de Jaime Rest, El laberinto del universo, en donde se afirma de Borges: "parece incuestionable considerarlo, en el conjunto de su obra, como un representante notorio del pensamiento nominalista, aristotélico". ${ }^{5} \mathrm{Diez}$ años más tarde, Juan Nuño colocará su interpretación en las antípodas de la anterior: "El hilo conductor de esos temas por el que se ha dejado guiar esta lectura es el extraño platonismo de Borges". "Probablemente, la polémica halle su origen en la famosa línea que Borges toma de Coleridge ("todos los hombres nacen aristotélicos o platónicos") $)^{7}$ y una de las consecuencias sean las lecturas diametralmente opuestas que Rest y Nuño hacen de textos como "Funes el memorioso" o "Tlön, Uqbar, Orbis Tertius": críticas idealistas para el primero, ${ }^{8}$ divertimentos nominalistas para el segundo. ${ }^{9}$ Sin embargo, tal vez la diferencia no sea tan determinante como parece a simple vista. Lo cierto es que ambos sistemas disponen del bagaje conceptual para crear ambas ficciones y para, posteriormente, dar cuenta de ellas: formas eternas, inmutables y sus respectivas instanciaciones empíricas por un lado; sustancias singulares y categorías universales por el otro. Así, es indistinto interpretar que en Tlön nadie cree "en la realidad de los sustantivos"10

${ }^{3}$ Jorge Luis Borges, “Tlön, Uqbar, OrbisTertius”, ed. cit., p. 436. Ver también Jorge Luis Borges y Osvaldo Ferrari, Diálogos, Barcelona, Seix Barral, 1992, p. 206.

${ }^{4}$ Jorge Luis Borges, Otras inquisiciones, "Epílogo", en OC, t. II, p. 153.

${ }^{5}$ Jaime Rest, El laberinto del universo, Buenos Aires, Fausto, 1976, p. 55.

${ }^{6}$ Juan Nuño, La filosofía de Borges, México, Fondo de Cultura Económica, 1986, p. 138.

${ }^{7}$ Jorge Luis Borges, Otras inquisiciones, "El ruiseñor de Keats", en OC, t. II, p. 96. Ver también Otras inquisiciones, "De las alegorías a las novelas", en OC, t. II, p. 123.

${ }^{8}$ Jaime Rest, op. cit., pp. 49-63.

9 Juan Nuño, op. cit., pp. 23-42 y 99-104.

${ }^{10}$ Jorge Luis Borges, “Tlön, Uqbar, OrbisTertius”, ed. cit., 436. 
porque sólo se confiere estatus ontológico a formas eternas o a universales; y del mismo modo, es indistinto interpretar que la capacidad de Funes para reconstruir "todos los sueños, todos los entresueños" 11 se apoya en su agudeza para percibir el más mínimo accidente de las sustancias o todas las instanciaciones de una forma idéntica. Por otra parte, una vez tomada esta decisión hermenéutica, basta con insertar una cierta distancia entre el narrador y el autor, sea la de la ironía, la de la crítica o la de la metáfora, para que podamos situarlo en la tradición opuesta a la que hayamos elegido asignarle a sus personajes. Que los habitantes de Tlön sean idealistas, no quiere decir que Borges lo sea. Inversamente, las virtudes mnemotécnicas de Funes, no tienen por qué comprometerlo con el nominalismo. Finalmente, las categorías de "platónico" y "aristotélico", tal como las emplea el escritor, no remiten a dos sistemas históricamente determinados, sino más bien a dos tendencias a lo largo de la historia de la filosofía, a tal punto que las encontramos a ambas dentro del aristotelismo medieval: "los nominalistas son Aristóteles; los realistas, Platón"12. Situar a Borges en el linaje del platonismo, en este nivel de generalidad, sería afirmar cosas tan contradictorias como que es racionalista o criticista; situarlo en el del aristotelismo, cosas tan contradictorias como que es empirista o pragmatista. No es que dé lo mismo una cosa y la otra; es que ambas localizaciones permiten dar cuenta de lo mismo, tal como una fotografía y su negativo.

De todos modos, este primer antagonismo está lejos de agotar las posibles filiaciones de la obra borgeana. En efecto, a principio de la década del '90, las opciones parecen haberse multiplicado. Así, Elena Altuna, en "Ficciones o la infinita repetición", lee a Borges como un precursor de la diseminación derrideana; José Luis de Diego, en "De Barthes a Pierre Menard", hace de Borges el precursor del semiólogo; y Serge Champeaux, en Borges et la métaphysique, entiende a Borges como un fenomenólogo que, tras observar los límites del lenguaje y la representación, señala una esfera exterior, la del sentimiento, que no obstante no puede señalarse sino desde el interior del lenguaje y la representación. Una mención especial merece, sin embargo, la interpretación que ubica a Borges en algún lugar entre el escepticismo y el esteticismo, a causa del número de adeptos que ha

${ }^{11}$ Jorge Luis Borges, "Funes el memorioso", ed. cit., 488.

${ }^{12}$ Jorge Luis Borges, Otras inquisiciones, "El ruiseñor de Keats", ed. cit., p. 96. Ver también Otras inquisiciones, "De las alegorías a las novelas", ed. cit., p. 123. 
suscitado ${ }^{13}$. Todas ellas convergen en el Epílogo de Otras inquisiciones, donde Borges escribe: "Dos tendencias he descubierto, al corregir las pruebas, en los misceláneos trabajos de este volumen. Una, a estimar las ideas religiosas o filosóficas por su valor estético y aun por lo que encierran de singular y maravilloso. Esto es, quizá, indicio de un escepticismo esencial". ${ }^{14} \mathrm{El}$ escepticismo sería el fundamento de un esteticismo; el esteticismo, el consuelo del escéptico. De este modo, afirma Silvia Magnavacca respecto de la relación de Borges con el neoplatonismo medieval: "El escepticismo sobre una filosofía ha mutado en fe literaria"15.

Ahora bien, exponente contemporáneo de los sistemas más pretéritos o precursor de las ideas más contemporáneas, en ningún caso descubrimos cuál es el valor de Borges para estas filosofías. Cuando el ejercicio hermenéutico consiste en afiliar a Borges a una tradición, a no ser que su mera presencia se interprete como valor agregado, no se dice nada sobre la posible ganancia para esa tradición. En ningún caso son interrogados los aportes filosóficos que Borges haya podido significar para la deconstrucción o para el escepticismo. Por otra parte, ¿̇en qué sentido debemos comprender este escepticismo? No es seguro que en un sentido más técnico que en el caso del platonismo y aristotelismo. ¿El escepticismo borgeano es indicio de una pertenencia filosófica o de una distancia respecto de la filosofía en su totalidad?

En efecto, la cuestión de si Borges es o no es un filósofo es, desde un punto de vista lógico, anterior a la cuestión de su identidad filosófica, y un

13 Ver por ejemplo Edgardo Gutiérrez, "Borges y la doctrina de la reversibilidad temporal", en Gregorio Kaminsky (comp.), Borges y la filosofía, Buenos Aires, Secretaría de publicaciones de la Facultad de Filosofía y Letras de la Universidad de Buenos Aires, 1994, p. 42; Carlos Alberto Bustos, Eduardo Pastor Osswald y Gustavo Varela, "Borges y Spinoza", en Gregorio Kaminsky (comp.), op. cit., pp. 89; Eckhard Volker-Schmahl, "La filosofía: un mito borgeano", en Gregorio Kaminsky (comp.), op. cit., p. 51; Ana María Berrenechea, La expresión de la irrealidad en la obra de Borges, Buenos Aires, Centro Editor de América Latina, 1984, pp. 112113.

${ }^{14}$ Jorge Luis Borges, Otras inquisiciones, "Epílogo", ed. cit., p. 153.

15 Silvia Magnavacca, "Neoplatonismo medieval en Borges", en Anales del Seminario de Historia de la Filosofia, Madrid, Servicio de Publicaciones de la Universidad Complutense, 2007, vol. 24, p. 83. 
segundo punto de aglutinación de la crítica. Es que al examinar esta cuestión, no es posible dejar de lado las contundentes declaraciones del escritor: "Quiere hacerse de mí un filósofo y un pensador; pero es cierto que repudio todo pensamiento sistemático porque siempre tiende a trampear"16. El problema es que, una vez citadas, se las pasa por alto como a una barrera en mal estado. Carla Cordúa lo advirtió correctamente, pues leemos en su "Borges y la metafísica":

Los mejores críticos adoptaron, como era lógico, estas declaraciones al decidir sobre las relaciones de Borges con la filosofía. (...) El problema comienza más allá de tal acuerdo. Pues apenas establecido que Borges no es un metafísico, los mismos que lo sostienen comienzan a hablar de la filosofía de Borges, de su metafísica idealista, del relativismo, del escepticismo $(\ldots)^{17}$.

Con esto en mente, releamos la confesión citada anteriormente: "Dos tendencias, decía Borges, he descubierto, al corregir las pruebas, en los misceláneos trabajos de este volumen. Una, a estimar las ideas religiosas o filosóficas por su valor estético y aun por lo que encierran de singular y maravilloso. Esto es, quizá, indicio de un escepticismo esencial". ${ }^{18}$ Esto es, quizá, indicio de un escepticismo esencial. "Quizá”, es el término más relevante de la observación, pues revela que esencial no quiere decir riguroso. Del escepticismo riguroso, Borges se distancia gracias a un escepticismo vulgar. Esencial, sin duda, pero vulgar. Implica esto que, de la filosofía, entendida como ciencia y profesión, como arte y práctica, se distancia gracias a su filosofía, entendida como conjunto de convicciones, valores o ideas. Otro tanto ocurre cuando dice: “Además, si yo tuviera que definirme, me definiría como un agnóstico, es decir, una persona que no cree que el

${ }^{16}$ Jean de Milleret, Entrevistas con Jorge Luis Borges, Caracas, Monte Ávila, 1970, p. 116.

17 Carla Cordúa, "Borges y la metafísica", en La Torre. Revista de la Universidad de Puerto Rico, Puerto Rico, La Editorial de la Universidad de Puerto Rico, 1998, año II, $N^{\circ} 8$, pp. 631-632.

${ }^{18}$ Jorge Luis Borges, Otras inquisiciones, "Epílogo”, ed. cit., p. 153. 
conocimiento sea posible". ${ }^{19}$ Lo importante no es el contenido de la definición, sino su condición: "si yo tuviera que definirme". Una vez más, a la hora de tomar partido, no sólo se toma partido por una posición que nos distancia del conocimiento, sino por una posición que nos distancia del hecho más elemental de tomar partido. Como si fuera poco, inmediatamente, no se define al agnóstico como alguien que sabe que el conocimiento no es posible, sino como alguien que cree que el conocimiento no es posible. A la luz de lo dicho anteriormente, no debemos comprender esta creencia ni siquiera como una fe, sino como una duda, como una posibilidad, como quien dice "creo que va a llover". En ambas declaraciones observamos, así, que el escepticismo y el agnosticismo no funcionan en Borges como escuelas propiamente dichas, sino como modos para distanciarse de la filosofía en su totalidad. Ahora bien, si no encontrábamos un aporte para la filosofía en el caso de una pertenencia particular, menos lo encontraremos en el caso de un "repudio a todo pensamiento sistemático".

Pero si dejamos ahora de lado las declaraciones de Borges, ¿en qué razones puede uno apoyarse para negarle la condición de filósofo? Este es el tercer punto respecto del que se ha pronunciado la crítica: ¿por qué no es Borges un filósofo? Es que, como lo expresa Cordúa, Borges no se dirige desde la literatura hacia la filosofía, sino desde la filosofía hacia la literatura. "Borges no apunta hacia la filosofía sino que viene de vuelta de ella". ${ }^{20}$ Él mismo lo explicó cuando decía:

No soy filósofo ni metafísico; lo que he hecho es explotar, o explorar -es una palabra más noble-, las posibilidades literarias de la filosofía. (...) Yo no tengo ninguna teoría del mundo. En general, como he usado los diversos sistemas metafísicos y teológicos para fines literarios, los lectores han creído que yo profesaba esos sistemas, cuando realmente lo único que he hecho ha sido aprovecharlos para esos fines, nada más"21.

19 María Esther Vásquez, Borges: imágenes, memorias, diálogos, Caracas, Monte Ávila Editores, 1977, p. 107.

${ }^{20}$ Carla Cordúa, op. cit., p. 633.

${ }^{21}$ María Esther Vásquez, op. cit., p. 107. 
Las letras no son para Borges la herramienta de un visionario que, en el fondo, tendría inquietudes filosóficas; al contrario, la filosofía es el material de un escritor cuyo deseo es, ante todo, lúdico. La labor del comentador se ve automáticamente transformada: ya no se trata de descubrir la verdadera filosofía implícita en la obra de Borges, sino de comprender qué operaciones realiza con tal o cual filosofía, o con las diversas filosofías. Es como si, en un caso y en otro, se intentase situar a Borges en una de las dos formas de pensar que él mismo distinguió: "Hay escritor que piensa por imágenes (...) y escritor que piensa por abstracciones $(\ldots)$ ". ${ }^{22}$ En el primer caso, se trataría de ver qué conceptos se utilizaron para engendrar las imágenes; en el segundo, a qué filosofías remiten las abstracciones. Pero observemos que, aun en la alternativa, siempre de un escritor se trata. Beatriz Sarlo entrelaza las dos opciones cuando afirma que Borges labra "una ficción filosófica reduplicada en una filosofía ficcional". 23 Permite así comprender que, sea atributo o sustancia de la ficción, la filosofía siempre es utilizada como material para la creación literaria.

No cabe duda que esta consideración de la obra de Borges permite detectar en ella un valor, a saber, su capacidad para engendrar universos paralelos reorganizando las piezas de las diversas ontologías. Sin embargo, no nos confundamos: este valor concierne a las letras y no a la filosofía, cuyas preguntas están dirigidas a este universo. Tenga la fuerza teórica que tenga, la decisión de invertir la dirección en la interpretación de Borges, de examinar su modo de ir desde la filosofía hacia la literatura y no de la literatura hacia la filosofía, implica dejar de lado la pregunta por el valor estrictamente filosófico de la obra de Borges. Con lo cual observamos que, se lo considere o no se lo considere un filósofo, ya sea porque en un caso la pregunta concierne a su pertenencia, ya sea porque en el otro concierne a parte de su apuesta literaria, la cuestión del valor de Borges para la filosofía queda relativamente pendiente. No obstante, si tanto ha hecho Borges con la filosofía, ¿no es de esperar que haya hecho algo también por ella? ¿En que podría consistir el aporte borgeano a la filosofía? Por definición, este aporte

22 Jorge Luis Borges, Otras inquisiciones, "Nathaniel Hawthorne", en OC, t. II, pp. 5051. Ver también Georges Charbonnier, Entretiens avec Jorge Luis Borges, París, Gallimard, 1967, pp. 116-117.

${ }^{23}$ Beatriz Sarlo, Un escritor en las orillas, Buenos Aires, Ariel, 1995, p. 131. 
no puede rastrearse en la obra de Borges, cuyo carácter filosófico está en duda, sino que debe buscarse en algún corpus filosófico.

Al igual que muchos de sus contemporáneos, ${ }^{24}$ Gilles Deleuze se sintió fuertemente atraído por la obra del escritor argentino. En la imagen de un laberinto en línea recta vio una metáfora de la revolución kantiana del concepto del tiempo: el tiempo ya no es la medida del movimiento, ya no se subordina al movimiento, no es "curvado" por el movimiento, sino que el movimiento se subordina al tiempo, a un tiempo independiente, a un tiempo "unilineal y rectilíneo". ${ }^{25}$ El jardín de los senderos que se bifurcan le ha servido luego para tareas tan diferentes como ilustrar la idea leibniziana de mundos incomposibles $^{26}$ y el empleo del flash-back en el cine de Mankievicz. ${ }^{27}$ Comentarios mucho menos generosos le motivaron la Historia universal de la infamia y el Manual de zoología fantástica, ya que, en el primero, Borges no habría reparado en la diferencia entre la traición y la trampa y, en el segundo, habría dejado deliberadamente de lado todos los problemas de deveniranimal. ${ }^{28} \mathrm{El}$ "Pierre Menard", finalmente, sería una excelente muestra de cómo comprender la historia de la filosofía: "la repetición más exacta, más estricta tiene como correlato el máximo de diferencia". ${ }^{29}$ Si Deleuze comprende la historia de la filosofía como un arte del retrato es porque consiste tanto en representar a otro como en representarse a uno mismo, tanto en copiar como en crear, tanto en repetir como en diferir exactamente lo mismo que sucede con el Quijote de la ficción de Borges. Sin embargo, es unas líneas más atrás de esta última mención en donde se

24 Baste recordar el célebre comienzo de Las palabras y las cosas (París,Gallimard, 1966, p. 7), donde Michel Foucault escribe: "Este libro tiene su punto de partida en un texto de Borges" (se refiere a "El idioma analítico de John Wilkins"), o los epígrafes borgeanos que Jacques Derrida inserta en la tercera sección de "La farmacia de Platón" (París, Seuil, 1972).

25 Gilles Deleuze, Critique et clinique, París, Minuit, 1993, p. 41. Salvo indicación contraria, todas las traducciones del francés son nuestras.

${ }^{26}$ Gilles Deleuze, Logique du sens, París, Minuit, 1969, p. 139.

${ }^{27}$ Gilles Deleuze, Cinéma 2. L'image-temps, París,Minuit, 1985, p. 68.

${ }^{28}$ Gilles Deleuze y Felix Guattari, Mille plateaux. Capitalisme et Schizophrénie 2, París, Minuit, 1980, p. 295.

${ }^{29}$ Gilles Deleuze, Différence et répétition, París, PUF, 1968, p. 5. 
juega, respecto de la relación entre filosofía y literatura, un parentesco más profundo entre la obra de Borges y la de Deleuze; aquel que nos permite reinterpretar la obra del primero. Un poco antes de referirse a la historia de la filosofía, afirma Deleuze que un libro de filosofía debe ser una especie de ciencia ficción, que la búsqueda de nuevas formas de expresión recién ha comenzado. ${ }^{30}$ ¿En qué sentido esta reflexión abre nuevas posibilidades hermenéuticas? La sentencia de Borges según la cual la filosofía es una rama de la literatura fantástica se revela escandalosa cuando se la comprende a la luz del escepticismo y el esteticismo mencionados. Es, en efecto, un atentado contra los valores prácticos y epistémicos tradicionales de la filosofía: la búsqueda del bien y de la verdad. La belleza, por su parte, dejaría de ser objeto de estudio para pasar a ser parte constitutiva del propio discurso. Pero la filosofía deleuziana ofrece un marco completamente distinto y la posibilidad de reinterpretar la sentencia de Borges de un modo en el que, lejos de ser la culminación de un escepticismo y esteticismo, se convierta en una sugerencia original tanto para el examen como para la producción de textos filosóficos. Comencemos entonces por comprender qué significa este acercamiento entre filosofía y literatura en el marco de la concepción deleuziana del discurso filosófico, para luego examinar su funcionamiento y medir su utilidad a nivel historiográfico y metodológico.

¿En qué consiste, según Deleuze, la literatura? En construir una lengua en la lengua. ${ }^{31} \mathrm{~A}$ diferencia de Saussure, Deleuze considera que la lengua, lejos de ser un sistema homogéneo y estable, es un sistema de elementos heterogéneos en variación continua. No existe lengua que no esté afectada por un coeficiente de variación. Es más, cuanto más tiende a estabilizarse una lengua, a consolidarse en un uso dominante, mayor es ese coeficiente que la afecta. ${ }^{32}$ Así el inglés, hoy idioma global, se ve amenazado por la penetración del español desde el sur, y padece la constitución de dialectos con sus propias reglas, tales como el llamado black-english. ${ }^{33} \mathrm{El}$ novelista, el poeta, no harían más que empuñar esta tendencia espontánea de

30 Ibid., p. 3-4.

${ }^{31}$ Gilles Deleuze y Felix Guattari, Mille plateaux. Capitalisme et Scbizophrénie 2, ed. cit., p. 123.

32 Ibid., p. 130.

33 Ibid., p. 118. 
la lengua a mutar. ${ }^{34}$ Sin duda por este motivo, Deleuze recurre a una frase de Proust para definir la literatura: "los grandes libros están escritos en una suerte de lengua extranjera" 35 .

Es porque la filosofía, según Deleuze, también construye una lengua en la lengua, que puede ser considerada, como lo hace Borges, como una rama de la literatura. "El bautismo del concepto solicita un gusto propiamente filosófico que procede con violencia o con insinuación, y que constituye una lengua en la lengua de la filosofía, no sólo un vocabulario, sino una sintaxis que alcanza lo sublime o una gran belleza." ${ }^{36} \mathrm{Al}$ igual que la literatura en general, la filosofía, efectivamente, constituye una lengua en la lengua, o para ser más precisos, implica una puesta en variación de la lengua, un uso absolutamente particular, un estilo. En un momento de gran afinidad con Borges, Deleuze afirma que "los grandes filósofos son también grandes estilistas". Se refiere a que, también en filosofía, existen grandes diferencias

34 Sin duda, es algo exagerado decir que lo que se constituye en una lengua es otra lengua. Deleuze apoya sus análisis en las tesis de Louis Hjelmslev, lingüista danés que definía a una lengua por su estructura, es decir, por el conjunto de leyes que rigen la conformación de palabras con sílabas y de sílabas con letras (Louis Hjelmslev, Le langage, Gallimard, París, p. 59). No toda combinación forma una sílaba o un signo real; la estructura es el conjunto de leyes que asegura esa formación. Por supuesto, Hjelmslev no ignoraba que una lengua puede modificarse a lo largo del tiempo. Por eso distinguió el concepto de uso del de estructura. Esas modificaciones son variaciones del uso de una lengua y no de su estructura, que es justamente lo que garantiza la identidad de una lengua a través de sus cambios. De lo contrario, deberíamos aceptar que "la lengua se modifica sin cesar, y que al despertar encontramos una lengua distinta que la noche anterior" (Ibid., p. 61-62). Ajustando la lingüística de Hejlmslev, es exactamente lo que afirman Deleuze y Guattari: "En un mismo día, un individuo pasa constantemente de una lengua a la otra. Sucesivamente, hablará como 'un padre debe hacerlo', luego como un jefe; a la amada, le hablará una lengua puerilizada; al dormirse se hundirá en un discurso onírico, y bruscamente volverá a una lengua profesional ni bien suene el teléfono" (Gilles Deleuze y Felix Guattari, Mille plateaux. Capitalisme et Schizophrénie 2, ed. cit., p. 119).

${ }^{35}$ Gilles Deleuze, Critique et clinique, ed. cit., p. 15 y 92.

36 Gilles Deleuze y Felix Guattari, Qu'est-ce que la philosophie ?, París, Minuit, 1991, p. 13. 
en el empleo de un simbolismo determinado. ${ }^{37}$ ¿Pero en qué consiste el estilo filosófico? ¿Qué rama de la literatura es la filosofía? "Por más que el vocabulario, en filosofía, forme parte del estilo, porque implica tanto la invocación de palabras nuevas, como la valorización insólita de palabras ordinarias, el estilo es siempre cuestión de sintaxis. (...) En filosofía, la sintaxis tiende hacia el movimiento del concepto." 38 Si el móvil de la literatura -y del arte en general, a juicio de Deleuze- para crear una lengua en la lengua, para forjar un estilo, es la creación de afectos y de preceptos, es decir, de nuevas maneras de sentir y de percibir, el móvil de la filosofía es la creación de conceptos, es decir, de dar consistencia a lo virtual o, en un lenguaje más clásico, de dar cuenta de la constitución de la experiencia. ${ }^{39} \mathrm{El}$ estilo siempre es definido como la puesta en variación de la lengua, el trabajo de la lengua. Pero esta variación, este trabajo, en filosofía, está orientado por la creación conceptual. Es para expresar un concepto novedoso que se forja un neologismo; es para rescatar un concepto en desuso o para darle un nuevo uso que se recurre a un arcaísmo. Si, a juicio de Deleuze, la instancia enunciativa en filosofía no son personajes literarios sino personajes conceptuales - Sócrates, para Platón; Zaratustra, para

${ }^{37}$ Una de las fuentes principales de Deleuze en esta materia es probablemente el epistemólogo francés Gilles-Gaston Granger, quien en su Ensayo de una filosofía del estilo (París, Odile Jacob, 1988, p. 8) define el estilo como una modalidad del uso de un sistema simbólico determinado. Esta definición le permite extender el concepto de estilo incluso hasta las ciencias formales y naturales. Así, podemos decir de una demostración que es elegante del mismo modo que decimos de una pincelada que es delicada. Granger pretende fundar un análisis de corte trascendental que examine las condiciones de posibilidad de la enunciación científica, una esfera totalmente independiente de la descripción de las intenciones o rasgos de carácter de los autores, objeto de la psicología. Ahora bien, si ciertos rasgos comunes permitirían diferenciar un estilo propio de una disciplina, también pueden detectarse diferencias particulares que distingan diversos estilos en su interior. Estas diferencias son justamente lo que aduce Granger en "Observaciones sobre el uso de la lengua en filosofía" para demostrar la imposibilidad de realizar el sueño leibniziano de un sistema simbólico formal unificado para la filosofía (Philosophie, langage, science, París, EDP Sciences, 2003, p. 95). Cada filósofo sería dueño de un estilo.

${ }^{38}$ Gilles Deleuze, Pourparlers, París, Minuit, 1990, p. 223.

${ }^{39}$ Para la definición deleuziana del concepto, remitirse a Qu'est-ce que la philosophie?, ed. cit., p. 10. 
Nietzsche - es porque eso que el filósofo intenta decir gracias a ellos, no son afectos o perceptos, sino conceptos ${ }^{40}$.

La frase de Borges según la cual la filosofía es una rama de la literatura fantástica, y la de Deleuze según la cual un libro de filosofía es una suerte de novela de ciencia ficción, son sin duda pronunciadas desde marcos muy disímiles y dependen de supuestos muy distantes. En el caso del argentino, como él mismo afirma, es el indicio de un escepticismo esencial que deriva en un tipo de esteticismo -tanto moral como epistémico-, o mejor dicho, en la decisión estética de explotar conceptos con fines literarios. Al francés, en cambio, sería imposible atribuirle tal actitud. Lejos de un escepticismo moral, atribuye a la literatura funciones éticas y políticas: la de sustraer la lengua a su uso dominante, ${ }^{41}$ la de permitirle al autor devenir otro, ${ }^{42}$ la de inventar un "pueblo que falta". ${ }^{43} \mathrm{Y}$ lejos de un escepticismo epistémico, le atribuye a la literatura, y al arte en general, la capacidad de revelar lo invisible e inaudible, lo que no vemos cuando miramos y lo que no escuchamos cuando oímos. ${ }^{44}$ Incluso el concepto de ficción en ambos autores es radicalmente distinto: en el caso de Borges es el triste juego al que estamos condenados desde el momento en que el conocimiento es imposible; en el caso del heredero del perspectivismo nietzscheano, es un nuevo criterio de verdad. Toda verdad es una ficción, no en el sentido de que no valga como verdad, sino de que expresa un punto de vista determinado e interesado. Las frases en cuestión, por lo tanto, no se dicen del mismo modo en un autor y en otro. Pero, como vemos, las diferencias no reposan en las respectivas concepciones de la filosofía, sino en las respectivas concepciones de la literatura. En ambos casos, la filosofía es una forma de literatura, y de literatura fantástica o de ciencia ficción.

Esta concepción, en el caso de Deleuze, no se limita a ser el objeto de una teoría del discurso filosófico, sino que se pone en funcionamiento en el marco de la historia de la filosofía, a la hora de comentar las filosofías del pasado. Tal es el caso de la célebre teoría de las tres Éticas, y de los

${ }^{40}$ Gilles Deleuze y Felix Guattari, Qu'est-ce que la philosopbie?, ed. cit., pp. 60-82.

${ }^{41}$ Gilles Deleuze y Felix Guattari, Mille plateaux. Capitalisme et Schizophrénie 2, ed. cit., p. 131.

42 Gilles Deleuze, Critique et clinique, ed. cit., p. 11.

${ }^{43}$ Ibid., p. 14.

${ }^{44}$ Ibid. 
aforismos y poemas nietzscheanos. ¿En qué consiste la teoría de las tres Éticas? No sin cierta poesía y cierto hermetismo, Deleuze afirma que la Ética de Spinoza son tres libros en uno: un libro de agua, un libro de fuego y un libro de aire. ${ }^{45}$ ¿A qué se refiere? Es un modo de decir que en la obra cumbre de Spinoza coexisten tres tipos de textos, cada uno con rasgos estilísticos distintos. Por un lado, está el hilo de las demostraciones, en un latín cuidado, donde predominan las deducciones, las referencias a pasos anteriores en la demostración, y en donde la instancia enunciativa es una primera persona del plural neutra, voz del more geométrico y de la razón. Pero por otro, están los escolios, prólogos, apéndices, que son como erupciones volcánicas que interrumpen el curso del río de la deducción. En efecto, son secciones que Spinoza intercala en el texto para rectificar prejuicios, defenderse de acusaciones, combatir ataques. Así, el apéndice al libro I considera los prejuicios relativos a la naturaleza divina; el prólogo al libro III discute con la definición cartesiana de las pasiones; el del libro IV, contra los prejuicios acerca de las ideas de bien y mal. Son textos de fuego en el sentido que son textos polémicos. $\mathrm{Y}$ como su finalidad es otra, naturalmente, sus rasgos estilísticos serán diferentes. La persuasión desborda la argumentación estricta y hecha mano a recursos como la insistencia o la caricaturización; la instancia enunciativa ya no es una primera persona del plural, neutra, sino una primera persona del singular que empuña su discurso; la prosa abandona el terreno de las abstracciones y se puebla de imágenes concretas como la de un plácido paseante a quien le cae una piedra en la cabeza ${ }^{46}$ o la de un caballo capaz de transformarse en hombre y en insecto. ${ }^{47} \mathrm{El}$ libro $\mathrm{V}$, sin embargo, no puede ser asimilado a ninguno de estos tipos de textos, en la opinión de Deleuze. Tiene otra velocidad: las demostraciones son más rápidas; la argumentación, más elíptica; las premisas permanecen supuestas. De ahí que Deleuze lo bautice como un libro de aire. Ahora bien, el señalamiento de los distintos recursos retóricos no tiene un valor en sí, sino en la medida que Deleuze los hace corresponder a los tres géneros de conocimiento que distingue Spinoza. El libro de agua es un libro escrito gracias al segundo género de conocimiento, la razón; es decir, procede por nociones comunes y según el orden de la

45 Ibid., p. 187.

${ }^{46}$ Spinoza, Ética, Libro I, “Apéndice”, Madrid, Trotta, 2000, p. 70.

${ }^{47}$ Spinoza, Ética, Libro IV, “Prólogo”, ed. cit., p. 185. 
lógica. Pero como Spinoza nos dice y repite que muchas veces no alcanza con la razón para persuadir a los hombres, es necesario un libro que recurra a la imaginación, al primer género de conocimiento, y que exprese lo mismo pero de un modo en el que el vulgo pueda entenderlo. Así procede el Antiguo Testamento con la sabiduría hebrea, ${ }^{48}$ así debe proceder también Spinoza con su ética. Finalmente, el libro V es un libro que, lejos de apelar a la imaginación, no apela tampoco a la razón, sino a la intuición. Las elipsis, los atajos no deben ser comprendidos como defectos del método o descuidos de la escritura, sino como la modificación de un método que ya no aspira a la exposición de nociones comunes, sino a la presentación de esencias que desbordan toda la discursividad y la deducción. Ahora bien, ¿debemos interpretar estos análisis deleuzianos como un examen independiente y paralelo a los análisis de los contenidos de la filosofía spinozista o son, al contrario, un modo de presentar y comentar esos mismos contenidos?

Es posible realizar la misma pregunta con el caso de la exégesis de la filosofía nietzscheana. Nietzsche y la filosofía se abre con la provocativa afirmación según la cual Nietzsche habría sido el responsable de introducir en la filosofía los conceptos de sentido y valor. $\mathrm{Y}$ a cada uno de estos conceptos correspondería un tipo de texto -nos dice Deleuze un poco más adelante, en un parágrafo dedicado al uso que hace Nietzsche de distintos símbolos e imágenes. "Pero nunca un juego de imágenes reemplazó para Nietzsche un juego más profundo, el de los conceptos y del pensamiento filosófico. El poema y el aforismo son las dos expresiones en imágenes de Nietzsche; pero estas expresiones están en una relación determinable con la filosofía." $49 \mathrm{Al}$ mismo tiempo que el fragmento nos recuerda que el estilo, en filosofía, siempre obedece a la creación de conceptos, nos indica que, en Nietzsche, el poema y el aforismo dependen de la creación de los conceptos de sentido y valor. ¿De qué modo? La misión del aforismo es determinar el sentido, dice Deleuze; la del poema, asignar el valor. ${ }^{50}$ En el pluralismo nietzscheano, a juicio de Deleuze, un fenómeno nunca tiene un sentido eterno e inmutable, sino que depende de la fuerza que se apropia de él. De ahí que el filósofo deba comportarse como hermeneuta y preguntar cuál es

48 Spinoza, B., Tratado teológico-político, XIII, Madrid, Alianza, 2003, pp. 163-169.

${ }^{49}$ GillesDeleuze, Nietzsche et la philosophie, París, PUF, 1998, p. 35.

${ }^{50}$ Ibid. 
su sentido. Es un psicólogo en la medida que debe leer los fenómenos como síntomas y diagnosticar un cuadro clínico. Así, la pregunta que plantea el método nietzscheano se distancia de la pregunta platónica ¿qué es lo $x$ ? para preguntar ¿quién? ¿Quién define a lo $x$ como $x$ ? Pero como el filósofo no es sólo un hermeneuta sino también un genealogista, como no pregunta sólo por la significación de un síntoma, sino que además, se preocupa por su nobleza, su dignidad, su salubridad, a la pregunta que interroga por el sentido, se le agrega la pregunta que interroga por el valor. Y así como cada género de conocimiento en Spinoza encuentra un tipo de expresión, en Nietzsche, cada momento del método, se enuncia gracias al aforismo y al poema. Poco importa que Deleuze tenga razón o no, que efectivamente la función de estos textos sea la que se le atribuye. Eso deberá determinarlo la crítica nietzscheana. Lo que intentamos poner aquí de manifiesto es el interés que exhibe Deleuze por los géneros literarios en filosofía. En este sentido, por un lado, el interés confirma las tesis generales acerca del discurso filosófico y muestra su funcionamiento concreto en la historia de la disciplina: la creación de conceptos implica un trabajo literario. Pero, por otro lado, levantan la sospecha de que ese trabajo no está simplemente implicado por un ejercicio conceptual independiente, sino que este ejercicio consiste justamente en ese trabajo. Dicho de otro modo: aforismo y poema no son simplemente los objetos de un análisis formal que Deleuze hace en crítico literario. Son, de minima, el modo en el que, como filósofo, elige presentarnos y explicarnos en qué consisten los conceptos de sentido y valor en la obra de Nietzsche; de maxima, parte del método mediante el cual Nietzsche construyó sus propios conceptos. En síntesis, no es tanto que la creación conceptual implicaría un trabajo literario como que la creación conceptual consistiría -entre otras cosas, sin duda- también en un trabajo literario. Tal vez sea, finalmente, un rápido examen de unos pocos procedimientos estilísticos del propio Deleuze lo que mejor permita comprender esta nueva forma de interpretar la idea borgeana según la cual la filosofía sería una rama de la literatura.

Un caso especialmente elocuente -dada la diversidad de formulaciones que motiva- es el del concepto de lo múltiple. ¿Cómo se define la multiplicidad en Deleuze? No como una totalidad o una unidad que se agrega a sus partes, sino como el sistema de relaciones entre las partes. No como una instancia trascendente que agruparía a las partes, sino como la red de sus interconexiones. Sus principios son los que Deleuze y 
Guattari le atribuyen al rizoma: la conexión y la heterogeneidad. ${ }^{51}$ Ahora bien, atendamos al modo en el que el propio Deleuze presenta su concepto. Dice, por un lado, que hay entender "lo múltiple" como un sustantivo y no como un adjetivo ${ }^{52}$. En el segundo caso, sería predicado de la unidad. Para darle toda su independencia, toda su singularidad, para que sea una forma de pensar la unidad y no un atributo de la unidad, hay que pensarlo como un sustantivo. Por otro lado, jugando con la homonimia que se da en francés entre la tercera persona del singular del verbo ser y la conjunción de coordinación, Deleuze nos dice que hay que sustituir el "EST" por el "ET"53. Significa, una vez más, que si queremos salvaguardar la singularidad de los entes en el seno de nuestra ontología, no debemos pensar las relaciones entre ellos bajo la forma de la predicación o de la atribución, sino bajo la forma de la conexión. Sin duda, uno puede considerar que estas aclaraciones no conciernen más que a la expresión del concepto y que su creación propiamente dicha las antecede. ¿Pero qué es su creación por fuera de estas expresiones? Lejos de desplegarse en una esfera muda y anterior al lenguaje, la creación de conceptos es ella misma actividad lingüística. Otra prueba la constituye el caso del concepto de acontecimiento, respecto del cual Deleuze y Guattari escriben que "articulo indefinido + nombre propio + verbo al infinitivo constituyen en efecto la cadena de expresión de base"54. ¿Por qué? Porque el artículo indefinido y el nombre propio tendrían la función de denominar singularidades no personales y, el verbo al infinitivo, la de señalar una temporalidad distinta a la de la realidad efectiva o actual. Pero, una vez más, no es sólo que Deleuze y Guattari no teman incorporar signos matemáticos o el uso de mayúsculas ("ET", "EST") en su prosa. Estas acrobacias podrían, en efecto, leerse como los movimientos requeridos para la expresión de ciertos conceptos. Es que, más importante, estos movimientos tienen lugar dentro de un discurso que hace referencia a sí mismo. Esta referencia está lejos de ser simple glosa metadiscursiva; es la indicación textual de que la creación de conceptos sucede en el lenguaje, gracias al lenguaje y, en cierto sentido también, contra el lenguaje. Un último

51 Gilles Deleuze y Felix Guattari, Mille plateaux. Capitalisme et Schizophrénie 2, ed. cit., p. 13.

52 Gilles Deleuze, Différence et répétition, ed. cit., p. 236.

53 GillesDeleuze y Claire Parnet, Dialogues, París, Flammarion, 1977, p. 70-71.

${ }^{54}$ Gilles Deleuze y Felix Guattari, Mille plateaux. Capitalisme et Schizophrénie 2, ed. cit., p. 322. 
caso notable -por el grado de popularidad que alcanzó- es el que concierne a la historia de la filosofía. Se ha vuelto un lugar común -y de manera ciertamente justificada- el afirmar que las monografías de Deleuze están escritas en discurso indirecto libre. Deleuze y Guattari, en Mil mesetas, afirmaron que el discurso libre es la primera determinación del lenguaje ${ }^{55}$. ¿A qué se refieren? La figura consiste en volver indiscernibles las instancias enunciativas. A diferencia del discurso directo o del indirecto, en el directo libre no es posible señalar marcas textuales (como los dos puntos o el pronombre relativo) para distinguir las diferentes voces. Es como cuando Flaubert escribe "La empleada volvió. La Señora iba a recibir al Señor"56. No es el narrador quien dice "Señora" o "Señor" sino la empleada. El discurso, no obstante, si bien mantiene la distinción, vuelve a los sujetos formalmente inseparables. Eso mismo debe hacer la historia de la filosofía según Deleuze: hablar en nombre de otro y en nombre propio simultáneamente sin confundir las voces. De ahí que la rebautice "arte del retrato filosófico"57 y que el "Pierre Menard" de Borges se vuelva un modelo. De ahí también que se suela afirmar que hay que leer los escritos monográficos de Deleuze como si hubiesen sido escritos en discurso directo libre. ¿Es simplemente una manera de decir? Sin duda, pero el punto es que en estas maneras de decir y gracias a estas maneras de decir se construyen los conceptos. No podemos, por lo tanto, concebir la relación entre palabra y concepto como una mera relación de denotación: las palabras son conceptos y los conceptos son palabras. No es aventurado pensar que es esto lo que condujo a Deleuze a tachar tres veces el término "nombre" (nom) y a reemplazarlo por el término "palabra" (mot) en una versión anterior de la introducción a ¿Qué es la filosofía?58 Probablemente, hacia el final de su carrera, estaba convencido de que una filosofía no es más -ni menos- que una "coordinación de palabras". Sin duda, puede parecer extraño para un filósofo que tanto se enfrentó al llamado giro lingüístico y a la limitación del

\section{Ibid., p. 97.}

${ }^{56}$ Este ejemplo propuesto por Philippe Mengue (Gilles Deleuze ou le système du multiple, París, Kimé, 1994, p. 249) nos resulta más claroque el del propio Deleuze (Cinéma 1. L'image-mouvement, París, Minuit, 1983, p. 106).

${ }^{57}$ Gilles Deleuze y Felix Guattari, Qu'est-ce que la philosophie ?, ed. cit., p. 55.

58 Archivos del Institut pour la Mémoire et l'Édition Contemporaines, fondo Félix Guattari, manuscrito "Introduction : ainsi donc la question...", signatura GTR2. Aa -07.02 .01 . 
pensamiento al lenguaje. Pero, nuevamente, las diferencias no conciernen a la concepción de la filosofía, sino a la concepción del lenguaje. Si hay motivos, en el pensamiento de Deleuze, para distinguir al concepto de la palabra, es porque se pretende liberar al pensamiento del lenguaje, hacer de él una potencia capaz de inventar lenguas. No quita que, para evitar la riesgosa trascendencia del pensamiento, haya afirmado también que esa liberación sucede en la lengua y dentro del lenguaje. Es la propia lengua la que se vuelve capaz de liberarse de sí misma, ejerciendo, tanto en un plano práctico como en un plano teórico, toda su potencia de invención.

La sentencia borgeana según la cual la filosofía es una rama de la literatura fantástica nunca cobró más sentido, pertinencia y actualidad filosóficas que en la obra de Deleuze. Esto no quiere decir que en la boca de uno y otro signifiquen lo mismo. Hemos visto que los marcos en los que se inscribe la fórmula son radicalmente distintos: escepticismo epistémico y moral en un caso, compromiso ético-político y confianza en la ciencia en el otro. En un caso, es ciertamente pronunciada por un filósofo; en el otro, probablemente, por un escritor. En el primero, funciona como una de las conclusiones necesarias de su pensamiento; en el segundo, como la aventurada sugerencia de una literatura que tenía el gusto de la provocación. Pero una permite iluminar la otra con una nueva luz y conferirle así pleno valor filosófico. La filosofía es una rama de la literatura en el sentido que consiste, entre otras cosas, en un trabajo literario: trabajo sobre la lengua, contra la lengua, pero en la lengua. Para leer filosofía hay que atender a las maniobras estilísticas que realizan los autores; para escribir filosofía, estamos obligados a efectuarlas. Sin duda por eso Henri Bergson decía que un filósofo debe también ser un escritor ${ }^{59}$. Es, por tanto, en un sentido metodológico que podemos hoy comprender la famosa declaración de Borges.

La filosofía de Deleuze ha permitido desarrollar y precisar esta comprensión. Sin embargo, es posible hallar en las tradiciones más diversas un interés por la relación entre la expresión lingüística y el ejercicio filosófico. Así, Gottfried Gabriel, en "¿La lógica como literatura? Observaciones sobre la significación de la forma literaria en Wittgenstein",

${ }^{59}$ Henri Bergson, Les deux sources de la morale et de la religion, París, PUF, 2003, p. 268. 
intenta probar cómo la forma aforística del Tractatus dista de ser una cuestión accesoria y ornamental y se presenta como la única posible para expresar sus $\operatorname{contenidos}^{60} \mathrm{y}$, en Leer a Bergson: 'Lo posible y lo real", historiadores de la filosofía, lingüistas y críticos literarios examinan en el ensayo de Bergson los distintos procedimientos encargados de la difícil expresión de la durée 61 . Por otra parte, ¿cómo olvidar aquella advertencia inaugural de Ser y tiempo? “Con respecto a lo rudo y 'feo' de la expresión dentro de los siguientes análisis, escribe Heidegger, puede ser oportuna esta observación: una cosa es contar cuentos de los entes y otra es apresar el ser de los entes. Para esta última tarea faltan no sólo en los más de los casos las palabras, sino ante todo la gramática"62. En cada uno de estos casos podremos preguntarnos si el trabajo literario es una necesidad discursiva posterior al ejercicio conceptual, o si ambas actividades encierran un vínculo más estrecho. Tal vez las respuestas nos conduzcan a distintas concepciones de la literatura y la filosofía. Pero en cualquiera de los casos habremos admitido esa afirmación que Borges tal vez no haya proferido como filósofo, que quizá incluso haya lanzado a modo de provocación, pero que hoy encierra plena pertinencia filosófica.

Recibido: 07/2012. Aceptado: 09/2012

${ }^{60}$ Gottfried Gabriel, "La logique comme littérature? Remarques sur la signification de la forme littéraire chez Wittgenstein", en Pierre Hadot, Wittgenstein et les limites du langage, París, Vrin, 2006, p. 111-127.

${ }^{61}$ Frédéric Cossutta (comp.), Lire Bergson: 'Le possible et le réel”, París, PUF, 1998.

${ }^{62}$ Martín Heidegger, Ser y tiempo, México, Fondo de Cultura Económica, 1997, p. 49. 